\title{
Tumoración quística en el muslo: Schwannoma del nervio ciático con diagnóstico inicial de quiste hidatídico, un caso clínico.
}

\author{
DOI: http//dx.doi.ORG/10.37315/SOTOCAV20212865635 \\ MONÍS GARCíA A, MIRANDA GÓMEZ I, OLMO VALERIANO I, MORENO VADILLO M, COLADO DOMÍNGUEZ J, \\ SANGÜESA NEBOT MJ, DOMÉNECH FERNÁNDEZ J.
}

SERVICIO DE CIRUGÍA ORTOPÉDICA Y TRAUMATOLOGÍA. HOSPITAL ARNAU DE VILANOVA, VALENCIA, ESPAÑA.

\begin{abstract}
Resumen
Introducción: los quistes hidatídicos son producidos por el parásito Echinococcus granulosus. La localización única en los músculos es poco frecuente. La masa quística puede confirmarse mediante ecografía o resonancia magnética (RM) y su diagnóstico diferencial puede presentar dificultades. Material y método: Se presenta el caso clínico de una tumoración en muslo con informe RM: "lesión quística encapsulada dependiente del bíceps femoral, que contacta con el paquete neurovascular ciático, siendo la primera posibilidad diagnóstica quiste hidatídico". Se pautó mebendazol y al mes se realizó exéresis del tumor, que no se encontraba dentro del vientre muscular sino desplazándolo, adherido al nervio ciático. El diagnóstico tras estudio anatomopatológico fue schwannoma del nervio ciático. Discusión y conclusión: en RM los schwannomas suelen verse como una masa adherida y excéntrica a un nervio, pero pueden presentar degeneración quística, imitando un quiste hidatídico. Ante una tumoración quística única muscular o perimuscular, cercana al paquete neurovascular, con pruebas sistémicas para enfermedad por parásitos negativas, se debe tener en cuenta al schwannoma en el diagnóstico diferencial.
\end{abstract}

\section{Summary}

Introduction: hydatid cysts are produced by the Echinococcus granulosus parasite. The single location in the muscles is rare. The cystic mass can be confirmed by ultrasound or magnetic resonance imaging (MRI) and its differential diagnosis may be difficult. Material and method: We present a case with a tumorous mass in thigh with MRI report: "encapsulated cystic lesion dependent on the biceps femoris, which contacts the sciatic neurovascular bundle, being the 1st diagnostic possibility hydatid cyst". Mebendazole was prescribed and after a month the tumor was excised, which was not located within the muscle but rather pushing it, attached to the sciatic nerve. Diagnosis after anatomopathological study was sciatic schwannoma. Discussion and conclusion: on MRI, schwannomas are usually seen as a mass adhered and eccentric to a nerve, but they can present cystic degeneration mimicking hydatidic cyst; Faced with a single muscular or perimuscular cystic tumor, close to the neurovascular bundle, with negative systemic tests for parasite disease, the schwannoma should be taken into account in the differential diagnosis.

Palabras clave: hydatid cysts; schwannoma; cystic mass; sciatic nerve

\section{Correspondencia:}

Ignacio Miranda Gómez. Servicio de Cirugía Ortopédica y Traumatología, Hospital Arnau de Vilanova, C/ Sant Climent 12, 46015 Valencia, España.

Correo electrónico: nachomigo@hotmail.com 


\section{INTRODUCCIÓN}

Los quistes hidatídicos son producidos por el parásito Echinococcus granulosus en estado de larva ${ }^{1,2}$. Los perros suelen actuar como huésped primario en la infección por Echinococcus granulosus, siendo las ovejas, vacas, caballos y ocasionalmente los humanos los huéspedes intermedios; por eso la incidencia de hidatidosis es mayor en regiones donde se cría ganado ovino y bovino ${ }^{2,3}$.

La localización más frecuente es en el hígado y los pulmones; la localización única en los músculos es poco frecuente $(0,5-5 \%)$, y se debe descartar que no haya quistes en otras localizaciones ${ }^{1-4}$. Los quistes hidatídicos pueden ser asintomáticos, o pueden dar sintomatología por el efecto masa por el crecimiento del tumor. Para confirmar el diagnóstico de hidatidosis se pueden utilizar pruebas serológicas, aunque no son positivas en todos los pacientes $^{1,2,4}$.

La masa quística puede confirmarse mediante ecografía o resonancia magnética (RM), siendo la RM la que aporta una mayor resolución e información ${ }^{4}$. La tomografía computarizada (CT) es útil, sobre todo en el caso de diagnóstico inicial de tumoración quística muscular única, para descartar la presencia de otras lesiones quísticas en tórax y abdomen ${ }^{3}$.

El diagnóstico diferencial, clínico, radiológico y serológico puede no ser concluyente, por lo que en muchas ocasiones la extirpación completa de la lesión es la mejor opción para el diagnóstico definitivo; se recomienda la utilización de medicación preoperatoria y postoperatoria para disminuir el riesgo de recurrencia ${ }^{4}$. La biopsia incisional está contraindicada por el riesgo de siembra o diseminación de la enfermedad ${ }^{1}$.

Los schwannomas son los tumores más frecuentes de la vaina de mielina de los nervios periféricos; son habitualmente tumores sólidos o heterogéneos, siendo los schwannomas quísticos de nervios periféricos poco frecuentes; pudiendo simular otras lesiones quísticas intra o extraneurales ${ }^{5}$.

El objetivo de este trabajo es presentar un caso clínico relativamente infrecuente por la localización de la lesión y que plantea un diagnóstico diferencial difícil.

\section{CASO CLINICO}

Se presenta un caso clínico. La paciente ha dado su consentimiento para la realización de los procedimientos y su consentimiento para la obtención de fotografías clínicas y su utilización con fines docentes o de investigación. Los autores manifiestan su adhesión al convenio de Oviedo y a la Declaración de Helsinki sobre investigación biomédica.

En la presentación del caso y redacción del trabajo se han seguido las recomendaciones de la declaración SCARE para casos clínicos quirúrgicos ${ }^{6}$.

\section{Caso clínico}

Mujer de 64 años, de raza blanca, que es remitida a la consulta de Cirugía Ortopédica y Traumatología por presentar una tumoración en la región posterior del muslo izquierdo. No refiere contacto habitual con animales ni ningún viaje reciente. El médico de cabecera le solicitó una resonancia magnética (RM). La RM fue informada como: "lesión quística encapsulada dependiente del músculo bíceps femoral izquierdo, de aproximadamente 33 × $39 \mathrm{~mm}$ de diámetros transversos máximos y $50 \mathrm{~mm}$ de diámetro caudal máximo, con otras lesiones quísticas de menor tamaño en su interior, que presentan realce parietal, sin asociar masas sólidas captantes ni cambios inflamatorios en tejidos blandos adyacentes. La lesión descrita contacta y comprime el paquete vasculonervioso ciático. La lesión descrita sugiere como primera posibilidad diagnóstica un quiste de origen parasitario (quiste hidatídico)" (Fig. 1).

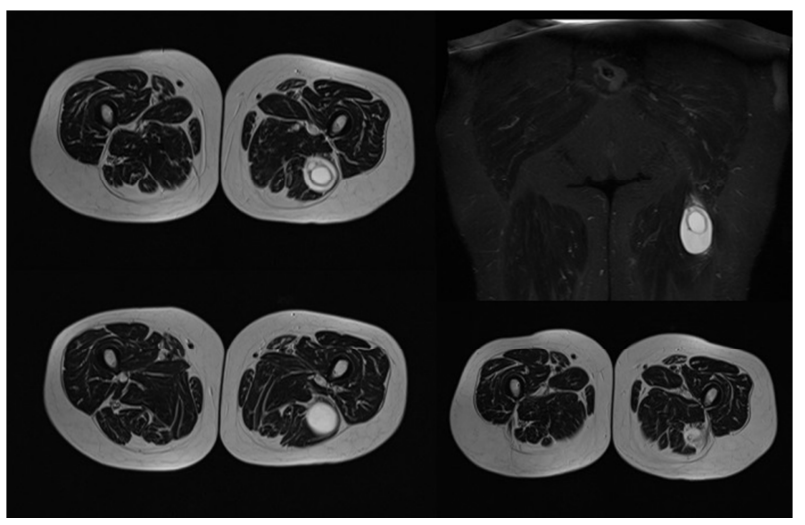

Figura 1. Imágenes de RM, donde se observa la lesión quística en la parte posterior del muslo.

La paciente refería que el bulto había ido creciendo muy poco a poco, que no le dolía, salvo cuando se sentaba y la silla comprimía justo sobre la zona, notando una molestia. No relataba ninguna otra sintomatología ni antecedente de interés. En la exploración física se palpaba una tumoración unos $10 \mathrm{~cm}$ por debajo del pliegue glúteo, en la zona central de la parte posterior del muslo, de $5 \times 8 \mathrm{~cm}$ de tamaño, dura, no adherida a la piel y no dolorosa a la palpación (Fig. 2).

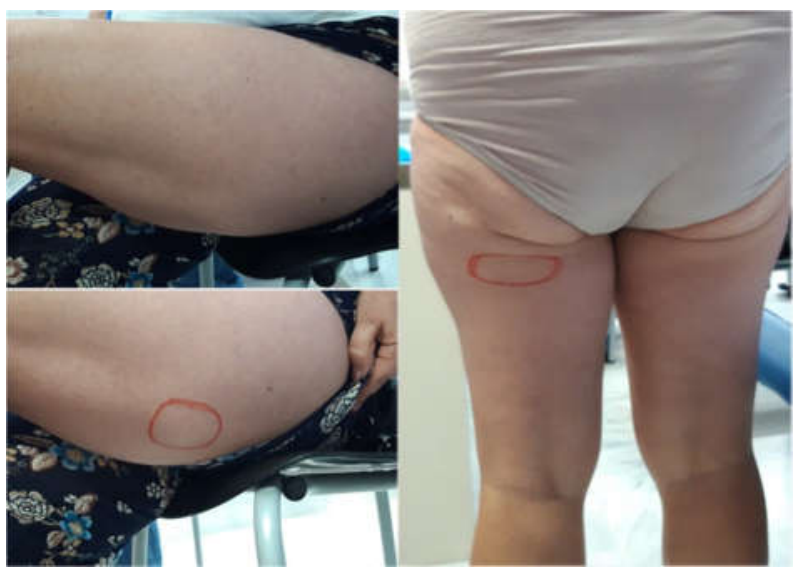

Figura 2. Fotos clínicas de la lesión, situada en la parte posterior del muslo, distal al pliegue del glúteo. 
Se solicitó valoración conjunta por médico internista especialista en enfermedades infecciosas. Se solicitó una tomografía computarizada (CT) tóraco-abdomino-pélvica, que no mostró ninguna alteración. La analítica de sangre con hemograma, bioquímica, coagulación mostró resultados normales y la determinación mediante inmunoanálisis de Ac IgG para hidatidosis fue negativa. Tras la valoración de las pruebas complementarias se mantiene el diagnóstico de quiste hidatídico único intramuscular sin afectación sistémica. Se pautó mebendazol $100 \mathrm{mg} / 12$ horas.

Siguiendo la indicación del especialista en enfermedades infecciosas, se programó la intervención tras un mes con la pauta de mebendazol, debiendo mantenerse el tratamiento tras la intervención hasta conocer el resultado del estudio anatomopatológico.

Intervención quirúrgica: bajo anestesia raquídea, en decúbito prono, se realizó una incisión longitudinal sobre la tumoración, mediante una disección roma se localizó la tumoración, que no estaba intramuscular, sino desplazando el vientre muscular del bíceps femoral, y adherida al nervio ciático (Fig. 3). Se disecó a proximal y a distal para referenciar el nervio ciático y se aisló la tumoración del nervio, consiguiéndose su exéresis marginal en un bloque. Se remitió la pieza $(6 \times 4 \mathrm{~cm}$ ) (figura 4) a anatomía patológica. Finalmente se realizó lavado y sutura por planos. Al día siguiente de la intervención, siendo la exploración sensitiva y motora del miembro normal, se dio de alta hospitalaria a la paciente manteniéndose el tratamiento con mebendazol $100 \mathrm{mg} / 12$ horas.

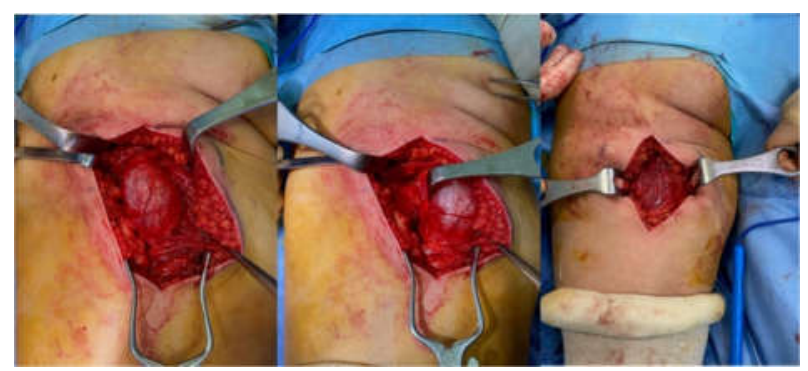

Figura 3. Campo quirúrgico donde se observa la tumoración (imagen izquierda); al separar la tumoración se observa justo debajo y en contacto, el nervio ciático (imagen central); y el lecho, después de resecar la tumoración (imagen derecha).

El estudio anatomopatológico indicó que la tumoración se trataba de un schwannoma, por lo que se informó a la paciente y se suspendió el tratamiento con mebendazol (13 días tras la intervención).

La evolución postoperatoria fue satisfactoria, con una adecuada cicatrización de la herida, sin alteraciones motoras ni sensitivas, permaneciendo la paciente asintomática 1 año tras la intervención.

\section{DISCUSION}

Se presenta un caso de una tumoración quística en la parte posterior del muslo. La presentación de un quiste hidatídico único intramuscular en el muslo o próximo a la región glútea, es poco frecuente, pero hay casos descritos en la literatura $^{1,2,4}$. Si se compara el aspecto que se observa en la RM del caso (Fig. 1) con la "Fig. 1" que presentan Zazo et al. ${ }^{1}$, se observa que la tumoración presenta unas características de imagen similares; y lo mismo sucede si se compara el aspecto macroscópico del tumor resecado (Fig. 4) con la "Fig. 3" del trabajo de Zazo et al. ${ }^{1}$.

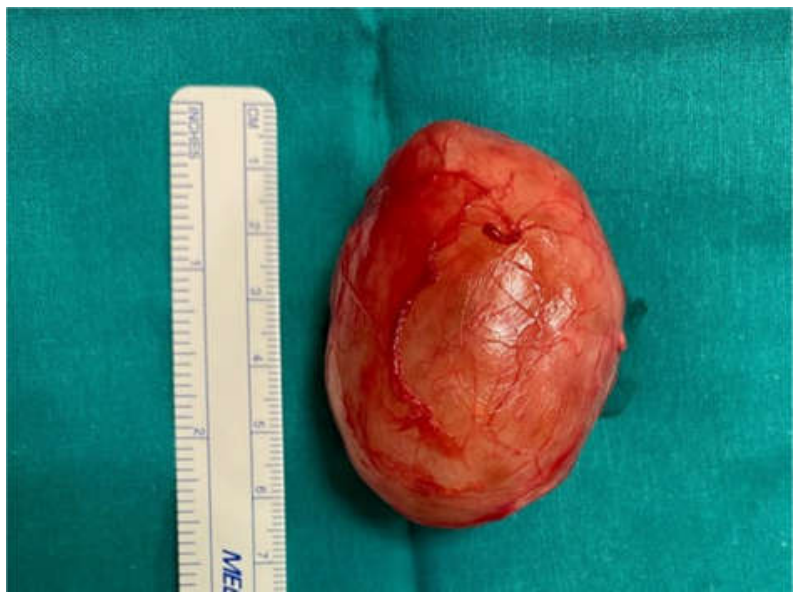

Figura 4. Imagen macroscópica de la tumoración resecada en bloque.

Ante la sospecha de un quiste hidatídico único intramuscular, tal y como recomienda la literatura, se realizó un TC de extensión y pruebas serológicas, siendo todos los estudios negativos, aunque esto no descarta que la lesión sea un quiste hidatídico $^{1-4}$. Igualmente, tal y como se describe en la literatura ${ }^{4}$, ante la sospecha por prueba de imagen de quiste hidatídico, se dio tratamiento antes y después de la intervención con antihelmínticos (mebendazol) y se realizó una resección en bloque de la tumoración. El diagnóstico anatomopatológico de la pieza estudiada no fue el esperado antes de la intervención (quiste hidatídico), sino que el diagnóstico fue de schwannoma del nervio ciático, lo cual concuerda con la impresión intraoperatoria de que la tumoración no estaba intramuscular, sino que estaba pegada al nervio ciático (Fig. 3), desplazando al músculo. Analizando de nuevo las imágenes de RM, se observan algunos cortes que sí que podrían haber hecho sospechar que el tumor no era un quiste hidatídico, sino un schwannoma, ya que, en las reconstrucciones sagitales, se puede ver que la tumoración quística depende del nervio ciático, situándose excéntricamente al nervio (Fig. 5). 


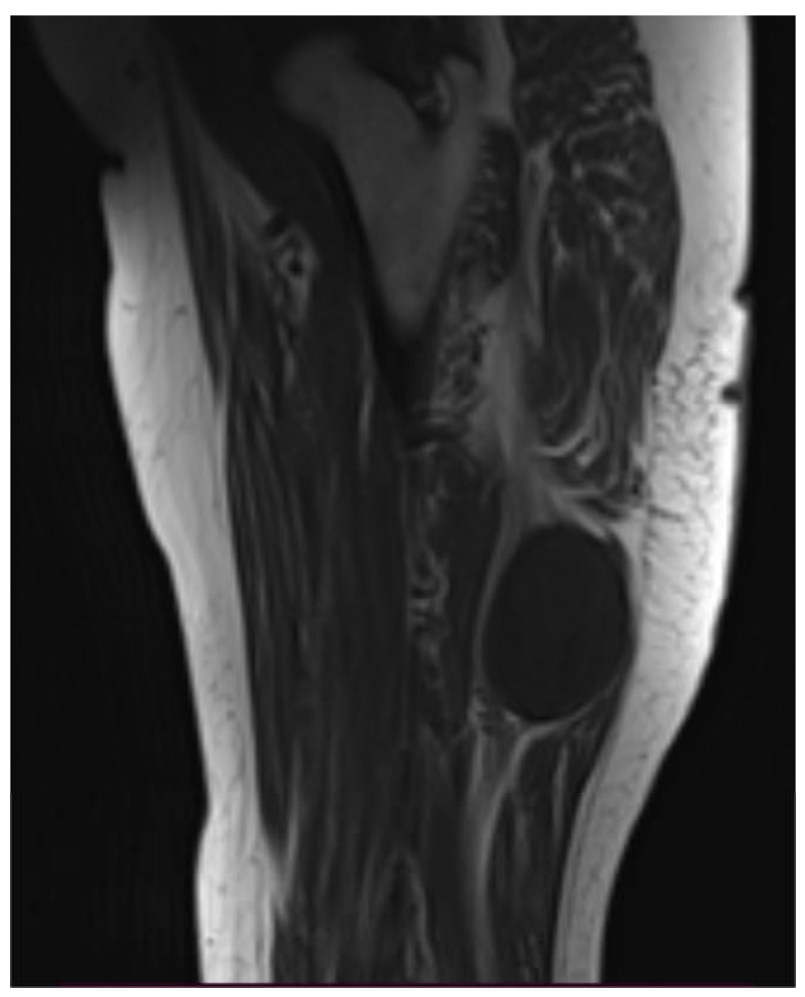

Figura 5. Imagen de RM donde se observa la tumoración excéntrica, dependiente del nervio ciático.

Aunque los schwannomas son el tumor más frecuente de los nervios periféricos, los del nervio ciático (a pesar de ser el nervio más largo) suponen menos del $1 \%^{7-10}$. A propósito de sus 2 casos, Telera et al. publicaron una revisión de la literatura y encontraron 23 casos descritos de schwannomas del ciático. En la revisión de Telera et al., todos los artículos presentaban solo 1 o 2 casos $^{7}$. A diferencia del caso que presentamos, el $80 \%$ de los pacientes, presentan parestesias o dolor irradiado tipo ciatalgia, y en ocasiones un signo de Tinel positivo a la palpación ${ }^{7,9}$. La RM es la prueba de imagen de elección para estudiar las tumoraciones de los nervios periféricos. Los schwannomas son tumores bien circunscritos y encapsulados, típicamente localizados de forma excéntrica en el nervio, hiperintensos en T2, y que se realzan con la administración de gadolinio de forma homogénea salvo en el caso de lesiones quísticas o con áreas necróticas, que se dan más en tumores muy grandes ${ }^{7,8,10}$. Se ha descrito la degeneración quística de los schawannomas, normalmente, si el tumor está sometido a presión (lo que es habitual en la parte posterior del muslo o en la zona glútea, al sentarse) o si ha sido lesionado ${ }^{7}$. La escisión quirúrgica es el tratamiento de elección; normalmente puede resecarse o enuclearse, conservando la continuidad del nervio y manteniendo su función ${ }^{8-10}$. Tras la resección, al igual que en el presente caso, desaparecieron los síntomas y la recuperación fue completa en más del $95 \%$ de los casos $^{7}$. El tamaño de los casos descritos es variable $(2,5-$ $15 \mathrm{~cm}$ ), siendo la mayoría, al igual que el caso de este trabajo, de un tamaño entre 3 y $8 \mathrm{~cm}^{7}$.

En conclusión, en RM los schwannomas suelen verse como una masa adherida y excéntrica a un nervio, suelen ser sólidos o heterogéneos, pero pueden presentar una degeneración quística, por lo que ante una tumoración quística única muscular o perimuscular, cercana al paquete neurovascular, con pruebas sistémicas para enfermedad por parásitos negativas, se debe tener en cuenta al schwannoma en el diagnóstico diferencial. El tratamiento de elección de los schwannomas del ciático es la resección quirúrgica y tienen buen pronóstico. 


\section{Bibliografía}

1. Zazo A, Zazo R, Shashaa MN, Alkarrash MS, Brimo Alsaman MZ, Niazi A. Uncommon musculoskeletal femoral hydatid cyst disturbs a female for a year: Case report. Ann Med Surg. 2020; 55:30-2.

2. Adıyeke L, Cakır T, Duymus TM, Aydogmus S. Unexpected Diagnosis in Gluteal Region -A Primary Intramuscular Hydatid Cyst: A Case Report. J Orthop case reports. 2018; 8(2):104-6.

3. Merad Y, Derrar H, Zeggai A, Belkacemi M, Belmokhtar Z, Adjmi-Hamoudi H. A rare primary hydatid cyst of the psoas muscle in a rural setting: A case presentation. Ann Med Surg [Internet]. 2020; 59(September 2020):86-8. Available from: https://doi.org/10.1016/j.amsu.2020.09.002

4. Samiee-Rad F, Emami A. An Iranian man with increased thigh mass due to a hydatid cyst. GMS Hyg Infect Control. 2020; 15:Doc20.

5. Panwar J, Mathew A, Thomas BP. Cystic lesions of peripheral nerves: Are we missing the diagnosis of the intraneural ganglion cyst? World J Radiol. 2017; 9(5):230.

6. Agha RA, Franchi T, Sohrabi C, Mathew G, Kerwan A, Thoma A, et al. The SCARE 2020 Guideline: Updating Consensus Surgical CAse REport (SCARE) Guidelines. Int J Surg. 2020; 84(November):226-30.

7. Telera S, Raus L, Vietti V, Pace A, Villani V, Galié E, et al. Schwannomas of the sciatic nerve: A rare and neglected diagnosis. A review of the literature with two illustrative cases. Clin Neurol Neurosurg [Internet]. 2020; 195(March):105889. Available from: https://doi.org/10.1016/j.clineuro.2020.105889

8. As-Sultany M, Ben-Ghashir N, Mistry A, Chandrasekar C. Giant schwannomas of the sciatic nerve. BMJ Case Rep. 2017; 2017:50-3.

9. Maes R, Ledoux P, De Brouckere G. A rare cause of sciatica: Sciatic nerve schwannoma: Report of one case with long subclinical course and misleading presentation. Sicot-J. 2020; 6:4-7.

10. Jerbi Omezzine S, Zaara B, Ben Ali M, Abid F, Sassi N, Hamza HA. A rare cause of non discal sciatica: Schwannoma of the sciatic nerve. Orthop Traumatol Surg Res. 2009; 95(7):543-6. 